\title{
Potências emergentes na ordem de redes: o caso do Brasil
}

\author{
Emerging powers in the network order: the case of Brazil
}

http://dx.doi.org/10.1590/0034-7329201400312

DANIEL FLEMES*

MIRIAM GOMES SARAIVA**

Rev. Bras. Polít. Int. 57 (2): 214-232 [2014]

\section{Introdução}

A estratégia de soft power não é uma novidade no comportamento internacional do Brasil. Com diferentes denominações, esse tipo de estratégia esteve influenciada por duas crenças que marcaram a política externa brasileira desde o início do século 20: por um lado a convicção de que é preciso construir e garantir a autonomia do país para suas escolhas externas, especialmente as relacionadas à estratégia de desenvolvimento; por outro lado a que busca uma ascensão do país na política global. Essas duas crenças articularam-se com interesses variados e orientaram estratégias diferentes de inserção internacional. O chanceler Barão do Rio Branco identificava no início daquele século um cenário internacional realista no qual os países deveriam garantir a soberania e expandir seu poder frente aos demais, isso a partir de recursos tanto materiais quanto simbólicos. Os recursos materiais seriam os militares e econômicos, enquanto os simbólicos, segundo ele, corresponderiam às alternativas usadas por países de poucos recursos e com vistas a ampliar sua presença nas relações internacionais. Na visão do chanceler, os elementos subjetivos seriam conquistados na esfera regional com a manutenção de relações especiais com um polo de poder em ascensão (os Estados Unidos, então). Na esfera global, consolidar os princípios de atuação externa que caracterizariam o comportamento do país contribuiriam para aumentar o prestígio internacional e as possibilidades de ação através do convencimento e da persuasão.

\footnotetext{
* German Institute of Global and Areas Studies, Institute of Latin American Studies, Hamburgo, Alemanha (Daniel.Flemes@giga-hamburg.de).

** Universidade do Estado do Rio de Janeiro, Programa de Pós-Graduação em Relações Internacionais, Rio de Janeiro, Brasil (miriamsaraiva@uerj.br).
} 
Com base nessa percepção cristalizaram-se linhas de atuação que podem ser vistas como pano de fundo de um comportamento de soft power, como a não intervenção, a solução pacífica de controvérsias e o respeito ao direito internacional. No decorrer do século, outras táticas foram incorporadas: a defesa da autodeterminação dos povos (ou dos estados); o aprimoramento do treinamento e capacidade de negociação dos quadros diplomáticos brasileiros; e, por fim, o esforço de construção da imagem de um país singular que, em função do tamanho e de outras características econômicas e sociais, poderia atuar como ponte entre os países pobres e as potências ocidentais.

As estratégias adotadas para atingir o objetivo de ampliação da participação do país em questões internacionais não foram constantes e se adaptaram a particularidades de diferentes contextos internacionais e preferências de forças políticas internas. A partir de 1960, com a Política Externa Independente (PEI), a expectativa de construir com os Estados Unidos relações que ampliassem os recursos de poder simbólico na dimensão regional deu lugar ao globalismo (Pinheiro 2004). Este abriu caminhos para o estabelecimento ou estreitamento de relações com países fora do eixo Europa/sistema interamericano e facilitou a projeção internacional do país. A PEI foi interrompida em 1964, dez anos antes do globalismo se consolidar definitivamente com o pragmatismo responsável. De todo modo, a diversificação de parceiros significou uma autonomia de comportamento em relação à potência hegemônica e deu maior poder de barganha frente às demais potências.

Seguindo no esforço de aumentar a capacidade de influir sobre os temas internacionais, o Brasil participou de fóruns de decisões da política global tendo como pano de fundo a utilização do soft power. É no início do século 21 que a ordem em rede aparece como um cenário ideal de atuação para o país tanto no sentido de aproveitar as oportunidades quanto para atuar na construção das redes. Burges (2012) aponta sete táticas de atuação que a diplomacia brasileira vem utilizando na última década, desde táticas mais inclusivas até outras com resultados bastante diferenciados para o Brasil e outros países. Mas todas têm em comum o exercício do soft power e o peso da argumentação diplomática, sempre com vistas a se projetar como potência global.

Em um cenário unipolar sistêmico, inserido em uma ordem baseada em princípios e valores ocidentais, o governo de Fernando Henrique Cardoso (19952002) estruturou uma estratégia de política externa com o objetivo de ascensão nas instituições da política global. O mundo era visto como marcado por um "concerto" de países com discurso homogêneo em defesa de valores universais, junto à tendência a formar regimes para garanti-los. Para formuladores brasileiros da política externa da época, de perfil institucionalista, uma das condiçōes da manutenção deste "concerto" seria a grande adaptabilidade da liderança norteamericana às demandas das potências e, em segunda instância, dos países médios ${ }^{1}$.

1 Gelson Fonseca Jr (1999) é um diplomata conhecido desta corrente. 
Esse cenário abriria espaços para o Brasil adotar uma posição de apoio aos regimes internacionais como forma de limitar a atuação das potências estabelecidas, gestoras dessas instituiçôes, uma vez que as regras do jogo internacional deveriam ser seguidas por todos os países incluindo os mais ricos. Segundo Fonseca Jr. (1999), essa posição orientar-se-ia, também, pela percepção da existência no novo cenário de alinhamentos variáveis.

A ideia de alinhamentos variáveis vem articulada com o universalismo histórico da política externa brasileira, mas apontando para algo novo: uma estratégia que conseguisse benefícios e articulações oportunistas a partir de uma avaliação e de uma escolha de parceiros frente a cada caso. Dentro dessa perspectiva, a diplomacia buscou um comportamento ativo nos foros multilaterais caracterizado como "global player" e optou pela adesão a regimes internacionais na área de segurança; assim como visou ocupar a posição também de global trader, com atuaçōes em diferentes mecanismos de negociações comerciais. Em relação à União Europeia houve um esforço de aproximação bilateral com seus países no campo político, identificando estes como parceiros do multilateralismo e dos princípios que embasariam o "concerto" de países. No entanto, essa expectativa não prosperou; a UE demonstrou preferência pela interlocução através do diálogo UE-Mercosul e um foro privilegiado UE-Brasil não foi considerado. No que diz respeito aos EUA, houve divergências referentes ao comércio internacional e ao protecionismo e, na América do Sul, enquanto o governo norte-americano incentivava a conformação da ALCA, o governo brasileiro criava obstáculos para atrasar a sua conclusão dando ênfase às experiências sub-regionais.

Mas os "alinhamentos variáveis" do Brasil não ficaram limitados às organizações internacionais vigentes ou às relaçôes com parceiros ocidentais tradicionais. A diplomacia brasileira buscou também aproximação às consideradas potências médias de grande porte, com destaque para a Índia, a China, a África do Sul e-embora não pertencente ao que se entende por Sul - também para a Rússia.

\section{Construir uma ordem mundial de rede}

Mas a multipolaridade do século 21 é fundamentalmente diferente das suas precursoras em três aspectos. Em primeiro lugar, o âmbito geográfico da multipolaridade foi estendido além do concerto europeu ou ocidental do século anterior. A nova ordem é mais global, com novos polos de poder na África, Ásia e América Latina. Em segundo lugar, os modos de atuação da política externa no sistema internacional de Estados mudaram drasticamente. Grande guerras ou conflitos entre superpotências já não são os meios dominantes para conduzir mudanças na ordem global. Desde a última década, as mudanças e inovaçóes estruturais na política global têm sido induzidas por negociações formais e informais e pelo estabelecimento de redes de política externa. E, consequentemente, no terceiro aspecto, a cultura processual das relaçôes internacionais mudou radicalmente. A cultura diplomática de uma ordem mundial vista como rede 
(networked world order) é marcada por um multilateralismo informal, através do qual coalizões em áreas específicas determinam os resultados das negociaçōes globais (Alexandroff e Kirton 2010).

Redes de política externa, como o G20, são caracterizadas por diferentes papéis dos seus Estados membros. Alguns deles podem formar coligaçôes localizadas no centro da rede, outros poderão ser marginalizados e forçados a uma posição secundária. Se decisões globais são cada vez mais questôes de negociação e coordenação de interesses nacionais em diferentes áreas globais, o status de certos Estados como agentes, mediadores e construtores de coalizões é crucial para os resultados dessas negociaçōes (Flemes 2009, 409).

Redes de política exterior representam um modo especifico de interação que se baseia em três princípios: os estados membros são interdependentes; as vinculaçôes entre eles podem servir para transmitir produtos materiais (por exemplo, armas ou dinheiro) ou produtos não materiais (informação, normas etc.); e padrōes persistentes de associação criam estruturas que definem, facilitam ou restringem o comportamento de suas respecticas políticas externas (Hafner-Burton et al. 2009:561-562). Os três princípios são mais visíveis em redes de política internacional que são motivadas por interesses comuns dos estados membros. Knoke define potência de rede como "preeminência em redes nas quais informação valiosa e recursos escassos são transferidos de um ator ao outro" (Knoke 1990).

Existe, porém, uma distinção entre redes de mediação, advocacia e substituição (Flemes 2013). Apesar do sucesso, potências emergentes continuam a ser excluídas das redes de mediação que abordam assuntos de segurança global, como o Quarteto do Oriente Médio. Redes de mediação são mecanismos que temporariamente aproximam Estados para resolver um problema específico de segurança. As potências participantes não partilham interesses e valores e, frequentemente, preferem maneiras diferentes de lidar com cada crise de segurança. Com exceção da China, que devido a seu assento permanente no CSONU é parte do grupo P5+1 sobre o Irã e das Conversaçôes de Seis Partes sobre a Coreia do Norte, as potências estabelecidas foram bem-sucedidas nesses domínios exclusivos da alta política. No entanto, a inclusão da Alemanha no grupo P $5+1$ e a iniciativa de mediação do Brasil e da Turquia sobre o programa nuclear iraniano apontam para o fim dessas prerrogativas.

Redes de advocacia ${ }^{2}$ são as redes de política externa entre partes ligadas por interesses comuns da política global (idem). As raízes dessas redes são, principalmente, as coligações de soft balancing, compostas por potências que não são do status quo. Redes de advocacia são agrupamentos horizontais, caracterizados por hierarquias planas e pequenas quantidades de membros. Seus membros criam laços fortes baseados em aspirações comuns de grande potência e também compartilham interesses em assuntos específicos. Três exemplos ilustram as características definidoras das redes de advocacia.

2 Traduzido do inglês "advocacy". 
No primeiro exemplo, os países do BASIC (Brasil, África do Sul, Índia e China) agem conjuntamente nos assuntos do clima, aderindo ao princípio de "responsabilidades comuns mas diferenciadas" desde a cúpula de Copenhague; embora nas negociações essa posição comum não tenha sido aceita pelas potências estabelecidas. Outro exemplo, o formato BRIC (Brasil, Rússia, Índia e China) BRICS (acrescido da África do Sul), até agora, tendeu, sobretudo, à reforma das instituições financeiras globais. Na primeira reunião de cúpula na Rússia, os países do BRIC, mas em especial a Rússia, sublinhou a necessidade de uma nova moeda de reserva mundial para reduzir a dependência do dólar americano. O terceiro exemplo refere-se a um interesse comum, compartilhado pela China e Rússia no âmbito do $\mathrm{SCO}^{3}$, de excluir os Estados Unidos de assuntos de segurança da Ásia e, mais especificamente, evitar a presença militar ou a intervenção dos EUA em qualquer de suas regiōes fronteiriças.

Além de seus interesses convergentes, algumas redes de advocacia compartilham normas e valores, como democracia e direitos humanos. Seus Estados-membros estão conectados por um sentimento comum reforçado por processos de socialização que ocorrem como subprodutos da sua colaboração continuada. Alguns deles, como os estados do IBAS (Índia, Brasil e África do Sul), também constroem comunidades de segurança inter-regional, conforme definido por Deutsch (1957).

As redes de advocacia, pautadas por valor e temas, contribuem para a construção da confiança e conseguem gerar e consolidar a solidariedade entre seus membros. Outras de suas funções internas incluem a coordenação de políticas e a produção e troca de conhecimentos entre potências emergentes. As funções externas mais importantes das redes de advocacia são o estabelecimento da agenda em negociaçōes globais, bem como o lobby em instituições formais, e a difusão de normas e ideias de seus membros no ambiente político global.

Redes de valor são um subtipo de redes de advocacia, e são mais adequadas à difusão de normas e valores no sistema internacional. O Fórum de Diálogo IBAS, bem como o G4 (incluindo potências estabelecidas, como Alemanha e Japão), baseiam suas afirmaçōes sobre os assentos permanentes do CSONU num discurso do poder civil que defende boa cidadania global e o multilateralismo democrático. Redes de valor foram formuladas e estimuladas entre os muitos que compartilham a experiência histórica de exclusão ou de marginalização dos processos globais de decisão.

Redes de substituição, por seu turno, são produto das pressões sistemáticas geradas por potências emergentes (Flemes 2013). Estas redes, como o G20, são heterogêneas e compostas por potências emergentes e estabelecidas. Por isso, reivindicam ser universalmente representativas. Redes de substituição têm como objetivo a substituição de instituições formais. Até então, o G20 ameaça incessantemente substituir ou anular o CSONU através de sua existência, se as instituiçôes de status quo provarem ser imunes a serem reformadas. Redes de

3 Do inglês Shangai Cooperation Organization. 
substituição são estabelecidas e poderiam eventualmente ser formalizadas, uma vez que as instituições anteriores de status quo tornar-se-iam ultrapassadas. Devido à quantidade de membros - maiores e mais diversificados -, as redes de substituição tendem a ser mais hierárquicas do que os tipos de rede acima mencionados. Como resultado, elas não são somente plataformas de discussão e negociação, mas também podem servir para a cooptação ou coerção sutil de países mais fracos. As redes de substituição serão cada vez mais úteis na coordenação da política global e na gestão de crises globais e bens públicos.

Dentro de uma rede de substituição, as potências emergentes beneficiam-se de sua qualidade de membros adicionais em uma variedade de redes de advocacia. Seus links de redes múltiplas resultam em papéis privilegiados como mediadores, que são as bases estruturais de influência na ordem mundial de rede. Pode-se mencionar os ministros das finanças do BRICS que formularam um comunicado conjunto na reunião do G20 em setembro/2009, em Londres, apelando para uma profunda revisão da distribuição de cotas das instituições de Bretton Woods. As vantagens competitivas das potências da rede surgem com seu acesso privilegiado à informação que é consequência de seus laços de confiança com vários outros Estados poderosos. Além disso, as experiências de cooperação e de processos de aprendizagem compartilhadas entre as potências da rede lhes permitem se relacionarem em base de maior credibilidade e previsibilidade em seu comportamento recíproco (Tsai 2001, 1001; Jones, Hesterley e Borgatti 1997). Níveis mais altos de confiança mútua resultam de uma credibilidade comparativamente maior nas ações e expectativas iniciadas entre tais aliados (Pappi \& Henning 1998). Essas vantagens comparativas são mais pronunciadas, e a posição do Estado mediador é mais influente, quando esse é o único ator que pode ligar vários conjuntos de Estados e resolver problemas interligados de coordenação multilateral.

Essas assimetria de informação conferem às potências de rede níveis elevados de autonomia estrutural em negociações do G20, entre outros fóruns. Se os atores estatais constroem mais ligações de redes, tornam-se mais poderosos e autônomos. No entanto, as oportunidades de rede são reduzidas com o aumento no número de relaçôes hostis que existem com as grandes potências. Nesse sentido, Brasil e África do Sul tem boas relações com todas as grandes potências estabelecidas, uma situação que poderia compensar parcialmente as suas deficiências de "hard power", em comparação com a China e a Índia, que mantêm uma relação de concorrência mútua, para não mencionar as várias restriçôes adicionais existentes no cluster de segurança da Ásia. No entanto, devido a suas várias instâncias de relaçõos de amizade com seus pares, as potências de rede são relativamente independentes das grandes potências, embora estas possam comandar recursos materiais de qualidade superior. Esse ponto também se confirma no caso de Estados vizinhos ou potências secundárias, que não estão dispostos a aprovar a liderança regional das potências emergentes.

$\mathrm{Na}$ atual ordem essas vantagens comparativas aumentam não só com o número de membros da rede, mas também com a dissimilaridade (clubes das potências 
estabelecidas, as potências emergentes, países em desenvolvimento, e os clubes de associação mista) e da frouxidão das diferentes redes de política externa. Dessa perspectiva, o Brasil e a Índia são os campeões da ordem de redes. Eles fazem parte de todas as redes de advocacia das potências emergentes, embora o status da Îndia de observador na SCO tenha suas limitaçóes, e o Brasil seja totalmente ausente nesta aliança, por causa do mandato regional. Por outro lado, também Índia e Brasil são as únicas potências emergentes que aderiram a redes da política externa das potências estabelecidas. Através do G4, ambos Estados mantêm "relaçôes especiais" com a Alemanha e o Japão, e, no grupo de preparação do G5 da OMC, negociaram de forma horizontal com os EUA e a UE.

A ordem mundial de rede ainda é hierárquica, mas muito menos do que as ordens uni, bi, ou multipolar do passado. Existem relaçōes hierárquicas dentro desta ordem, sobretudo dentro das redes de substituição. A hierarquia das redes de política externa é influenciada não só pelos recursos materiais relativos de seus membros, mas também pela capacidade institucional, o profissionalismo diplomático e a eficácia da negociação. Neste sentido, a eficácia significa a necessidade de promover indiretamente muitas relações diferentes, investindo menos em canais bilaterais.

Mesmo que a hierarquia continue a ser uma categoria útil para a compreensão das redes de política externa, sua estratificação pode finalmente ser melhor compreendida como padrôes consequentes de centro e periferia. Embora seja verdade que o padrão centro-periferia, de uma forma semelhante à natureza da estrutura hierárquica, caracteriza-se pelo centro de alto status, as relações entre o centro e a periferia nas redes de política externa são, por sua vez, marcadas muito mais pela reciprocidade do que nas instituições formais. Atualmente o centro do G20 é composto por quatro potências estabelecidas, os Estados Unidos, França, Reino Unido e Rússia, e quatro potências emergentes, Brasil, China, Índia e África do Sul. As potências civis, Alemanha e Japão, estão em uma categoria própria. À margem do processo de decisão global após a Segunda Guerra Mundial, elas, no entanto, conseguiram aderir à moda de coalizão soft balancing das potências emergentes, embora sejam parte de diversos clubes estabelecidos, como o G8, enquanto membros de segunda grandeza. Como resultado, semelhante à Rússia, que como uma potência estabelecida em declínio agora participa nas redes de advocacia de potências emergentes, a Alemanha e o Japão posicionam-se de forma vantajosa nas redes com grandes oportunidades de mediação entre seus sócios do G8 e do G4 nas redes de substituição.

A semiperiferia do G20 é composta por duas outras potências de rede, a União Europeia e a Turquia. A UE sofre com sua falta de status de ator e agência, e com a ausência de uma política externa e de segurança harmonizada. Essas deficiências comprometem seu potencial como um mediador de paz no Oriente Médio ou como ponte para a África. A Turquia é cultural e geopoliticamente predestinada a ser um construtor de pontes entre as potências estabelecidas do Ocidente e o mundo muçulmano. Embora a iniciativa da Turquia em parceira com o Brasil frente ao Irã não tenha auferido êxito, ambos os jogadores conseguiram garantir seu lugar 
no Oriente Médio e, como tal, continuarão a oferecer os seus serviços de mediação na região. O "comportamento diletante" dos mediadores turco-brasileiros, como analistas políticos colocaram, pode ser transformado em um argumento para sua inclusão futura em uma rede de negociadores mais experientes. Como afirmou o primeiro-ministro britânico, David Cameron, em discurso em Ancara, a Turquia seria o país europeu com "a maior chance de persuadir o Iră". (The Guardian, 27 Julho 2010).

\section{Negociações transversais na nova ordem}

Em geral, três fatores explicam a influência dos atores estatais na ordem multipolar: capacidades relativas materiais, institucionais e ideológicas. Estratégias de política externa são os meios pelos quais essas capacidades são convertidas em influência política. A riqueza econômica relativa de um país é um pré-requisito para as capacidades militares e as estratégias coercitivas. Da mesma forma, a legitimidade e a credibilidade podem ser convertidas em estratégias discursivas. É verdade que o poder material ainda é, e no futuro previsível continuará a ser, a condição prévia para grande influência no sistema internacional de Estados. Mas é demonstrado aqui que, para a definição do status global dos Estados na nova ordem, recursos militares e econômicos perdem terreno para os recursos institucionais, em especial, a capacidade da rede, assim como as vantagens de informação e as capacidades de mediação. Habilidades diplomáticas distintas de coalizão e mediação trazem novos padrões de assimetria. Posiçôes com altos níveis de prestígio na rede central são objetivos de política externa, comumente justificados por razões de direito próprio ou porque implicam em uma maior visibilidade com potencial para aumentar a atratividade do Estado na arena global. Estados poderosos em posições de prestígio na rede gradativamente se convertem em alvos de propostas cooperativas e se promovem, assim, ao intercâmbio de informações.

Nesse contexto, os EUA, bem como a UE e, especificamente, a Alemanha têm se empenhado, nos últimos anos, na construção de parcerias estratégicas com o Brasil, a China, a Índia e a África do Sul, além de outros países emergentes. Inicialmente, esta abordagem bilateral parece benéfica porque, como um negociador canadense de comércio comentou, "negociar com os Estados Unidos é como dormir com um elefante". Mas as redes de advocacia das potências emergentes refletem uma abordagem superior, porque na ordem de rede a eficácia diplomática está condicionada à capacidade de promover, indiretamente, muitas relaçóes diferentes. Assim, Slaughter $(2009,112)$ tem razão ao argumentar que o ator central na ordem de rede será aquele com maior número de conexões.

No livro de Joseph Nye $(2010,8)$ sobre o futuro do poder, o autor confunde a lógica de blocos de contrapeso (counterbalancing blocs) e as redes de política externa, ao propor o reforço da posição de rede dos Estados Unidos via construção de uma aliança de interesses com o Japão e a Europa, de modo a prejudicar um alinhamento do leste asiático. Mas os impactos e resultados das estratégias de 
balancing e exclusão são muito limitados na ordem mundial de rede visto que as divergências e as convergências dos interesses nacionais não dependem de sua localização geográfica. A composição das redes de advocacia muda, segundo os interesses e necessidades de cada área de governança global. Parafraseando as palavras de Bill Clinton, "It's the policy, stupid!"

A situação, no entanto, pode se tornar ainda mais complicada com a ampliação das agendas discutidas no interior das redes. No caso do G20 ocorre um transbordamento para além das questôes econômicas e financeiras. Na reunião de cúpula de 2010, os problemas globais como corrupção e segurança energética e alimentar foram incluídos na pauta da rede. No contexto pós-Copenhague, analistas e diplomatas olharam para o G20 como um fórum alternativo para vencer um impasse entre os EUA, a UE e a rede BASIC. Áreas problemáticas como a saúde global e as políticas comerciais poderiam ser ali também negociadas. Uma agenda estendida pode transformar as cimeiras em locais de negociações complexas (cross-issue bargaining) como, por exemplo, as reduções dos subsídios agrícolas em troca da redução das emissões de $\mathrm{CO} 2$.

No âmbito de negociações intertemáticas, os Estados têm que cumprir duas condições prévias para não serem manipulados pelos demais. Primeiro, há uma necessidade crescente de coordenação e formulação de diretrizes de competência para a política externa no nível estatal. Os ministérios de meio ambiente, saúde, relaçôes exteriores e comércio precisam coordenar seus interesses específicos, para não ser atirados uns contra os outros durante uma negociação multilateraltransversal (cross-policy). Segundo, antes de ser capaz de construir coalizóes, um Estado tem que encontrar aqueles jogadores que têm interesses similares em assuntos específicos e aliar-se com eles, porque acordos políticos transversais não são necessários e possíveis a todo momento. Stewart Patrick do Council on Foreign Relations argumentou que o objetivo da diplomacia mudou de "gerir o equilíbrio de poder" para "administrar a interdependência global” (2010, 50). Como resultado, ele incentiva os EUA a construir redes de advocacia "convocando clubes diferentes para diferentes fins." A mesma proposta é pertinente para a Alemanha e o Japão, potências de rede que ainda não usam suas oportunidades como tal. Em vez de construir novas redes de advocacia, porém, a Alemanha estoicamente sublinha as prioridades do processo de integração europeia e o cultivo das relaçôes transatlânticas - o mesmo acontece no caso do Japão e suas relações transpacíficas - como os pilares centrais de sua política externa. Os tomadores de decisão da política externa alemã parecem temer que os EUA e as grandes potências europeias possam interpretar parcerias inovadoras entre a Alemanha e as potências emergentes como um afastamento dos parceiros tradicionais e em busca de novos horizontes.

No entanto, exemplos como o acordo nuclear indo-americano e a aliança estratégica de armamento entre França e Brasil, em vigor desde 2008, demonstram o espaço de manobra existente na ordem multipolar. Falta explorar esses novos canais de autonomia e flexibilidade, que não só promovem um retorno a Vestfália, mas também à perda das oportunidades da ordem de rede. Peter Wittig, embaixador 
alemão na ONU, apontou na direção certa ao afirmar, após a eleição da Alemanha como membro não permanente do Conselho de Segurança (2011-2012), que enquanto um assento permanente para a UE é um projeto a longo prazo, uma cadeira alemã é a prioridade imediata. Embora a reforma do sistema da ONU permaneça altamente incerta, o Conselho de Segurança não permanente do Brasil, Alemanha, Índia e África do Sul sublinha a correspondência relativa entre a ordem de status quo e as mudanças de poder globais.

A reação geral da ONU para a evolução do G20 foi defensiva. Depois de ter inicialmente aceitado a ideia de um G20, oferecendo sua sede como o local da cimeira, as Naçóes Unidas foram gradualmente marginalizadas do processo, em vez de se estabelecer como um componente essencial do modelo G20, como fez a UE. Cooper e Helleiner (2010) argumentam, em artigo sobre o G20 como um "governo econômico mundial", que as Nações Unidas ao invés de trabalhar de forma sistemática para integrar a sua agenda à do G20, na verdade, permitiu que a Assembleia Geral se tornasse o local principal de resistência organizacional para o G20.

No que diz respeito ao papel dos EUA no processo de reforma da ordem mundial, um profundo equívoco prejudica a colaboração construtiva com as potências emergentes. Quando a Secretária de Estado, Hillary Clinton (2010), dirigiu-se ao Council on Foreign Relations, em setembro/2010, declarou que a resolução de problemas da política externa exige "ligar naçôes, regiōes e interesses que só a América pode. [...] Os Estados Unidos podem, devem e vão liderar este novo século. [...] E países como China e Índia, Turquia, México, Brasil, Indonésia, África do Sul, assim como a Rússia têm que aceitar [...] cumprindo um conjunto de regras inerentes ao processo". A estratégia de selecionar e escolher algumas potências emergentes que a partir da perspectiva dos EUA são atores responsáveis não parece ser promissora numa ordem global de rede.

As potências emergentes não concedem aos Estados Unidos legitimidade e autoridade única para definir as regras do jogo ou o que é um comportamento responsável. Um estilo de liderança dominante, que esquece os princípios de justiça e igualdade relativa dos Estados não é suscetível porque a ordem mundial de rede é mais transparente, mais horizontal, e recíproca que suas antecessoras. Os EUA é o jogador mais visível, pois ainda reside no centro da atual ordem, sendo também o alvo preferido de críticas, muitas vezes alimentadas pelo antiamericanismo. Um estilo de liderança egoísta faria os ganhos necessários de soft power extremamente difíceis de se obter.

E, mais impressionante, os EUA não estão mais em posição de poder nomear novos tomadores de decisão. Se as potências emergentes não percebem que são tratadas de forma equitativa, elas podem exercer influência de sua posição privilegiada de rede para remover as instituições formais pelas redes de substituição. Neste sentido, a inclusão ativa das potências emergentes em redes de mediação que enfrentam as crises de segurança mundial será um sinal decisivo da política externa futura dos EUA. Uma diplomacia balanceada de rede pode ser a chave 
para superar a falha histórica de iniciativas de paz no Oriente Médio. Os Estados Unidos devem aprender com as potências de rede e tornar-se um mediador honesto para ambas finalidades: preservar sua posição central e ganhar credibilidade e legitimidade na ordem mundial de rede.

\section{O Brasil em uma ordem multipolar e o papel das redes}

A ordem global fragmentada dos anos 2000 foi marcada pela emergência do pluralismo em termos de ideias e comportamentos, assim como pela ascensão de novos atores que buscam modificar o equilíbrio nas decisões sobre temas de dimensão global. "Ativa e altiva", a política externa brasileira do governo de Luiz Inácio Lula da Silva (2003-2010) encontrou um cenário internacional favorável para a novidade dos mecanismos de redes, com caráter minilaterais, especialmente para a interação entre diferentes atores e para fazer frente a diferentes temas.

O governo de Lula trouxe um novo perfil para a política externa brasileira. A convicção diplomática do governo de Cardoso nos regimes internacionais foi substituída pelo comportamento proativo com vistas a incidir nesses regimes através de táticas de persuasão e soft balancing em favor dos países do Sul ou em benefício próprio. Segundo Gratius (2011) em período de construção de uma nova ordem política, o Brasil buscou favorecer posições anti-hegemônicas e multipolares.

A ascensão de Lula trouxe uma novidade no processo de formulação de política externa que teve impactos na estratégia externa. Como no caso de Cardoso, Lula também manifestou vontade política de elevar o Brasil à posição de potência global. O policy-making da política externa apoiou-se em sua vontade política e contou com uma articulação entre os autonomistas do Itamaraty - tributários do desenvolvimentismo -, desenvolvimentistas das agências econômicas e atores políticos vinculados ao $\mathrm{PT}^{4}$ (Partido dos Trabalhadores).

Os autonomistas defendiam uma projeção autônoma e proativa do país na política internacional, visando a revisão das instituiçôes internacionais e a aproximação com países emergentes que teriam características comuns com o Brasil ${ }^{5}$. Este comportamento, identificado como revisionismo soft $t^{6}$, teve como principal objetivo a ascensão do país à posição de potência global. Autonomistas e desenvolvimentistas de agências de governo identificavam a projeção internacional como um instrumento de acesso a mercados externos, como mecanismo de fortalecimento do país nas negociaçôes econômicas internacionais, e também como canal para a projeção das empresas brasileiras no exterior. O programa

\footnotetext{
4 Sobre este tema ver Saraiva (2010).

5 Eram vistos como países com dimensões continentais, e importância regional, não alinhados a áreas específicas e nem polos centrais de poder que seriam, portanto, candidatos potenciais a se destacarem em uma nova ordem internacional.

6 Maria Regina S.de Lima, expondo sobre "As bases conceituais da Política Externa Brasileira" no Seminário Iniciativa México Brasil, LACC/FIU, Miami, 13/05/2010 apresenta essa tipologia para o comportamento externo do Brasil.
} 
de governo do PT para 2003-2006, diferentemente do costume brasileiro de orientar o debate político para temas internos, apontava em primeiro lugar um projeto de política externa direcionado para o papel do Brasil como mediador de tensões internacionais, para a construção de um mundo mais equilibrado e para a integração na América do Sul como elemento capaz de impulsionar o desenvolvimento nacional.

Segundo Vigevani, Ramanzini Jr., Favaron e Correia (2008), a política externa de Lula caracterizou-se pelo reforço das crenças na autonomia e no universalismo. Guiada por essas crenças, e articuladas ao objetivo de ascensão à potência global, a diplomacia brasileira empenhou-se em construir diferentes tipos de coalizões e redes prioritariamente com parceiros do Sul, resguardando sempre a autonomia brasileira. Os mecanismos aqui identificados como redes de advocacia e de substituição tornaram-se o principal instrumento de atuação internacional do país. O governo investiu no aumento e preparo do corpo diplomático para atuar nas diferentes dimensões da política internacional e na abertura de novas embaixadas.

Pinheiro e Milani (2010) chamam a atenção para a pluralização de atores no processo de formulação. Na dimensão governamental, o desenvolvimento da cooperação sul-sul do Brasil com países vizinhos e africanos aumentou a presença de outros ministérios como o da Saúde, de Ciência e Tecnologia e de Agricultura na cooperação internacional, assim como o BNDES (Banco Nacional de Desenvolvimento Econômico e Social) ganhou peso em financiamentos externos.

No início do mandato, o governo implementou iniciativas para fortalecer a candidatura do Brasil a membro permanente do CSONU. Como credenciais para a candidatura brasileira, foram deixados de lado os princípios e valores tradicionais do Ocidente e optou-se por defender valores identificados com os países do Sul e que afetariam a estabilidade internacional: melhor distribuição de benefícios do comércio internacional, o desenvolvimento (com uma definição imprecisa) e o combate à pobreza. $\mathrm{O}$ combate ao terrorismo não foi assumido como prioridade.

A candidatura foi defendida por dois caminhos. Em primeiro, através de apoios de países considerados importantes pelos policy-makers. Neste caso, o governo buscou conseguir de líderes do P-5 um posicionamento de defesa da candidatura brasileira. Frente à América do Sul, colocou-se como representante de um bloco de poder regional buscando, com isso, o apoio dos demais. Nos dois casos, porém, o Brasil não recebeu a resposta esperada. As potências do P-5 dividiram-se entre ausência de posicionamento e palavras vagas de apoio. No caso sul-americano, o Brasil enfrentou forte oposição da Argentina e, mais discreta, de outros países. $\mathrm{O}$ projeto brasileiro de montar um sistema regional de poder e responder como bloco a temas da política global trouxe desconfianças nos países vizinhos. A iniciativa de projeção global foi identificada pelos vizinhos como recurso para o Brasil atingir interesses próprios ${ }^{7}$.

7 Sobre o Brasil e a América do Sul, ver Saraiva (2014). 
Mas foi através de dois mecanismos de redes de advocacia que o Brasil exerceu maior pressão internacional na defesa de sua candidatura. O G4, entendido como uma rede de valor, foi um mecanismo importante através do qual a diplomacia brasileira fez pressão e buscou modificar o formato vigente das Nações Unidas. A candidatura brasileira ao assento permanente do CSONU não teve êxito, apesar dos esforços brasileiros colocados no tema. Mas outra iniciativa minilateral, com características de rede de advocacia que inclui, entre outras, esse tema, foi levada adiante.

A coligação de soft balancing montada entre o Brasil, África do Sul e Índia no tema dos medicamentos contra o HIV, durante o governo Cardoso, consolidouse como uma rede com a criação do Fórum IBAS, que teve como motivaçôes principais o debate e a pressão em questões relacionadas à ordem internacional e à reforma da $\mathrm{ONU}$, assim como o intercâmbio tecnológico entre os pares. Neste caso, caminharam juntas aspirações revisionistas dos três países, tanto políticas quanto econômicas.

Dentro da dinâmica de construção dessas iniciativas minilaterais baseadas nos três princípios definidos por Hafner-Burton et al. (2009, 561-562), em parceria com a Índia, a diplomacia brasileira trabalhou na montagem, em 2003, do G20 comercial. O Grupo, formado pouco antes das negociações de Cancun com vistas a incluir o fim dos subsídios agrícolas na Rodada Doha, com países do Sul (e a China), atuou na defesa da perspectiva brasileira nas negociaçóes realizadas na OMC e significou uma ação em rede com outros países em desenvolvimento. O G20 foi um fórum importante de atuação da diplomacia brasileira e logrou condicionar o avanço das negociações da Rodada à inclusão da questão dos subsídios à agricultura em sua agenda. No decorrer das tentativas de negociação, porém, as posiçôes divergentes no interior foram se confirmando e o Grupo perdeu sua unicidade.

O sucesso da diplomacia brasileira na estruturação do G20 deu lugar a outro tipo de interação: a participação do Brasil - e da Índia - no grupo de preparação da reunião da OMC em Genebra, em 2004, junto com a UE, os EUA e a Austrália (o G5). Foi uma experiência de interlocução com potências ocidentais na qual o papel sugerido de representante do G20 acabou sendo desvirtuado em função de interesses mais pontuais do governo brasileiro (Schirm 2010). O multilateralismo informal do G20 garantiu para o Brasil uma margem de autonomia grande para defender posições próprias nas negociações. Em termos comerciais, o governo reforçou questóes político-estratégicas e empreendeu uma política incisiva de busca de mercados tradicionais e novos, que resultou no aumento das exportaçôes e no superávit brasileiro.

O BRIC/BRICS pode ser considerado a principal experiência em rede da diplomacia brasileira. Nesse caso, o Itamaraty buscou aproveitar todos os espaços abertos pela classificação inicial do Brasil como um BRIC (países realmente emergentes) estruturando uma rede de advocacia a partir de um fato político. Em 
2006, foi constituído enquanto mecanismo de interação e com foco no sistema financeiro internacional, inicialmente orientado para um esforço de mudança no ordenamento do FMI.

Como em outros casos, o BRIC não restringe o espaço de manobra do Brasil caso haja discordância, mas contribui para alavancar as posiçóes defendidas pelo Brasil na política global. Não comporta práticas intervencionistas entre seus membros preterindo, portanto, questôes de direitos humanos tal como defendidos pelo Ocidente. No intento de adaptar ou modificar as regras vigentes desde dentro das instituiçóes - através da entangling diplomacy - o governo brasileiro articulou o tema dos direitos humanos com o desenvolvimento, em detrimento dos tradicionais direitos políticos e civis ${ }^{8}$.

$\mathrm{Na}$ percepção da diplomacia brasileira, esses países teriam características semelhantes ao Brasil, assim como coincidiriam na expectativa de reordenamento do sistema internacional. E, como traço relevante, tenderiam a buscar a cooperação internacional como forma de se contrapor a ações unilaterais de grandes potências - o soft balancing?.

Com praticamente os mesmos parceiros - com exceção da Rússia - a diplomacia brasileira favoreceu a estruturação da rede de advocacia de política externa e transnacional sobre as negociaçōes do meio ambiente. O BASIC foi um instrumento de confluência de posições e da defesa de um modo alternativo de enfrentar a questão ambiental, com o foco na necessidade de desenvolvimento dos países do Sul considerando-se os problemas aportados pela mudança climática. Por outro lado, com uma diplomacia atuante por dentro de mecanismos estruturados por potências estabelecidas, o Brasil participou do Fórum das Grandes Economias de Energia e Clima, assim como da Convenção-Quadro das Naçôes Unidas sobre Mudança do Clima ${ }^{10}$.

Mas ao final do governo Lula, a formação do G20 financeiro foi o coroamento da estratégia diplomática de criar redes e, pela primeira vez, uma rede identificada como de substituição. O mecanismo propiciou ao Brasil, simultaneamente, a opção de tentar modificar as regras trazendo junto a si as potências estabelecidas, assim como a alternativa de criar coalizões em seu interior em casos de desafio às percepçôes tradicionais. Com os países do BRIC, o Brasil pressionou as potências estabelecidas para conseguir modificar a dinâmica das instituições financeiras internacionais e garantir espaço de atuação e decisão dos países emergentes em seu interior. No entanto, a autonomia brasileira não foi comprometida e as preferências assumidas pelo Brasil em outros temas não tiveram vínculos necessários com esses parceiros.

8 Sobre esse tema, ver Schittini (2011)

9 Ver documento "O repensar do Itamaraty e da Política Externa Brasileira”, citado Barros (1994, 134).

10 Sobre este tema, ver” (Viola e Franchini 2013). 


\section{Retração da diplomacia presidencial e o impacto nas redes}

O governo de Dilma Rousseff (desde 2011) herdou de seu predecessor, do mesmo partido, um intricado de diferentes redes, coalizões e mecanismos de interação de política externa. Seu governo mostrou disposição, a nível discursivo, de manter a estratégia de política externa adotada pelo governo de Lula: a trajetória revisionista nas instituiçôes internacionais e a atuação nos foros multilaterais com o perfil de representante dos países do Sul. O grupo autonomista foi mantido nas principais posições do Itamaraty e a variedade de atores envolvidos na política externa conquistada durante o governo Lula se manteve. A preferência pelo envolvimento de agências de governo, alternativas ao Itamaraty e mais técnicas, nas negociaçōes, foi uma marca do processo decisório. A tendência desenvolvimentista foi reforçada (Saraiva 2014).

O primeiro movimento, portanto, foi de continuidade nas redes estabelecidas durante o governo de Lula. Porém, a diplomacia presidencial foi reduzida e a vontade política demonstrada por Lula de articular visóes favoráveis a um esforço diplomático de projeção externa do país não teve continuidade. A política externa de resultados concretos de curto prazo, de caráter técnico, tornou-se prioritária. Segundo Veiga e Rios (2011), questōes econômicas de curto prazo teriam ocupado um papel central na política externa em detrimento de ações políticas de projeção internacional.

A busca incessante do assento permanente do CSONU não foi abandonada, mas perdeu impulso. O Fórum IBAS reduziu o foco de ação no tema, apesar das declarações que defendem a participação de seus membros no Conselho. As atuações no G4 ficaram limitadas a reuniōes durante as Assembleias Gerais da ONU. E o BRICS, embora tenha avançado muito durante o período no que diz respeito a articulações em fóruns multilaterais, não chegou a formular uma posição conjunta de apoio ao assento permanente do Brasil; Rússia e China não manifestaram claramente o apoio para tal. $\mathrm{Na}$ América do Sul, o governo brasileiro trabalhou para romper com a oposição argentina e construir uma posição de consenso no interior da região.

Em relação a questôes ambientais, a afirmação ao direito do país - e dos países do Sul - ao desenvolvimento foi mantida mas, como em outras áreas, impacto e iniciativas foram reduzidos. O BASIC seguiu com reuniōes ministeriais, mas nas reuniões de 2011 e 2012 a diplomacia brasileira sustentou uma posição descolada das defendidas pela Índia e pela China "em relação às metas de redução das emissóes" (Viola e Franchini 2013, 63). A formulação do documento da Rio+20, que teve lugar no Brasil em 2012, não exprimiu uma liderança brasileira no tema nem as posições de países emergentes. O texto foi considerado vago por cientistas e não redundou em um capital diplomático para o Brasil como havia sido a Rio 92.

A incorporação da África do Sul ao então BRIC limitou as áreas de ação do Fórum IBAS, causando uma sobreposição de pautas e agendas das duas redes e eventuais conflitos de lealdade nas quais a primeira rede se fortaleceu em detrimento 
da segunda. Para a diplomacia brasileira, as ações alinhadas com o BRICS foram prioritárias, enquanto as iniciativas do IBAS ficaram restritas ao Fundo IBAS e à interação entre as respectivas sociedades civis. Em 2013, por falta de empenho da presidência brasileira, a cúpula entre os três parceiros não foi realizada.

A atuação do Brasil no BRICS, porém, foi o ponto foco renovado da política de Dilma Rousseff. As cúpulas ocorreram e foram assinados acordos em diversos campos, embora o grupo não tenha avançado em uma institucionalização restritiva. Seu perfil de rede e característica da não obrigação foram mantidos. Houve uma inciativa de articulação de posições na ONU, que se materializou na convergência de votos no CSONU em temas da agenda internacional como os enfrentamentos internos na Líbia e na Síria. Nos dois casos, a posição brasileira foi de manutenção dos princípios da não intervenção e da solução pacífica de controvérsias. Em relação à defesa dos direitos humanos, apesar do apoio brasileiro a algumas resoluções do $\mathrm{CDH}$ contra o Irã e a Coreia do Norte, em pouco tempo a posição brasileira convergiu com as posiçốes de outros parceiros do bloco mantendo a distância das posiçōes europeias e norte-americanas. A tensão entre defesa dos direitos humanos e defesa da soberania dos países é presente na agenda dos parceiros do bloco, assim como a preferência por um cenário não hegemônico com poucas regras e um sistema internacional pluralista de Estados soberanos.

Mas foi no campo financeiro que o BRICS avançou mais. A criação de um banco para financiar projetos de infraestrutura nos países do bloco foi consolidada na cúpula de 2014, junto com o estabelecimento de mecanismos de cooperação entre os respectivos bancos de desenvolvimento nacionais. Foi criado um fundo de apoio aos países do bloco caso experimentem dificuldades em seus respectivos balanços de pagamentos. Este passo - que ainda está no porvir - significa o estabelecimento de mecanismos vinculantes que reduzem as margens de autonomia dos países envolvidos. No campo do G20 financeiro, estruturou-se uma coligação de países do bloco que resistiu às tentativas das potências ocidentais de introduzir regulamentações para controle do fluxo de capitais. Mas não conseguiram que fossem implementadas as decisōes referentes a mudanças nas instituiçōes financeiras internacionais. A recomposição das economias norte-americana e de parte dos países da Zona do Euro reduziu os espaços de manobra dos países emergentes nas negociaçôes do Grupo.

No tema da segurança internacional, a diplomacia brasileira buscou assumir um papel de liderança. Sem desprezar o princípio da "responsabilidade de proteger", Dilma Rousseff, em seu primeiro ano, sugeriu uma ideia correlata, mas diferente - "responsabilidade ao proteger" - como estratégia mais apropriada para garantir a proteção de indivíduos em casos de crise ${ }^{11}$. A "responsabilidade ao proteger" sugere que medidas coercitivas devem ser implementadas apenas como última opção

11 Ver Rousseff, Dilma. Discurso na abertura do debate geral da 66a Assembleia Geral das Naçōes Unidas. Nova York, 21/Set./2011. Disponível em: http://www.itamaraty.gov.br/sala-de-imprensa/discursos-artigos-entrevistas-eoutras-comunicacoes/presidente-da-republica-federativa-do-brasil/discurso-na-abertura-do-debate-geral-da-66aassembleia-geral-das-nacoes-unidas-nova-york-eua-21-de-setembro-de-2011-1 Disponibilidade: 15/09/2014. 
e, em caso de intervenção militar, o Conselho de Segurança deve monitorar sua implementação. Essa ideia não teve apoio das potências estabelecidas que defendem a importância de haver flexibilidade em situaçôes de crise para se poder mobilizar diferentes instrumentos de assistência e coerção (incluindo recursos militares) (Gratius e Grevi, 213). Os parceiros do BRICS também não demonstraram apoio explícito. Embora tenham posições que questionam o mecanismo de "responsabilidade de proteger", não manifestaram apoio ao Brasil (com exceção do governo sul-africano). Ou seja, a diplomacia brasileira não conseguiu estabelecer uma coalizão em defesa de sua nova formulação no campo da segurança.

Por fim, nas negociações da Rodada Doha, se durante o primeiro mandato de Lula o G20 comercial foi uma iniciativa importante, com Dilma Rousseff as negociações foram marcadas por dificuldades de unificar posiçôes ou manter uma rede sólida que pudesse articular os países emergentes ou modificar as preferências das potências estabelecidas. $\mathrm{O}$ combate contra o protecionismo foi o elemento de convergência, mas sem maiores desdobramentos. A grande conquista do Brasil, na esteira da diplomacia de redes construída no governo anterior, foi a vitória para o cargo de diretor da OMC do diplomata brasileiro Roberto Azevêdo. Azevêdo contou com votos de diferentes continentes, com destaque para a África e a América do Sul.

\section{Conclusão}

A ordem internacional em rede dos anos 2000 é diferente da ordem globalizada dos anos 1990 e introduz distinções que beneficiam os países emergentes. O convívio entre fragmentação e redes variáveis é um campo propício para a ascensão de novos atores e para a relativização do poder das potências estabelecidas durante o século 20. Trata-se de uma ordem em construção, na qual as expectativas das potências estabelecidas e emergentes, assim como suas iniciativas, contribuem em si mesmas para a sua consolidação.

Para a política externa revisionista de Lula, com o objetivo de ascensão do país à posição de potência global, a ordem em rede foi um cenário profícuo. A diplomacia brasileira soube tanto aproveitar as oportunidades abertas pelas redes quanto implementar iniciativas para reforçá-las. A interação através de redes foi o principal instrumento da política externa brasileira e, em 2010, o Brasil desfrutava de uma posição diferente na ordem internacional de estados. A ascensão de Dilma Rousseff, porém, restringiu a atuação do Brasil nas redes. Sem modificar o discurso de política externa nem abandonar formalmente as iniciativas levadas adiante pelo governo anterior, reduziu o empenho presidencial em participar de variados fóruns internacionais. A atuação da diplomacia possibilitou uma manutenção descendente da participação brasileira nas redes.

Mas a ordem em redes segue em curso e, dentro dos padróes históricos do comportamento externo brasileiro baseado na autonomia e na busca de ascensão internacional, seguirá sendo um bom cenário para iniciativas vigentes e futuras. 


\section{Referências}

ALEXANDROFF, A. S., \& KIRTON, J. J. (2010) The "Great Recession" and the Emergence of the G-20 Leaders' Summit. In ALEXANDROFFS. E COOPER, A.F (eds.), Rising States, Rising Institutions. Challenges for Global GovernanceWaterloo: Centre for International Governance Innovation.

BARROS NETTO, S. do R. O Brasil e a Rússia. In FONSECA JR, G. e CASTRO, S.H.N. de (orgs), Temas de Politica Externa II - vol. 2. Brasília, FUNAG/SP, Paze Terra, 1994, p. 117-136. (IPRI. Coleção de Relações Intenacionais v.20).

BURGES, S. (2012) Strategies and tactics for global change: democratic Brazil in comparative perspective. Global Society, vol. 26, No 3, p. 351-368.

CLINTON, Hillary (2010) Council on Foreign Relations Address by Secretary of State Hillary Clinton, Transcrito em http:/www.cfr.org/diplomacy/council-foreign-relations-addresssecretary-state-hillary-clinton/p19840. Disponibilidade: 02/09/2014.

COOPER, A.F. \& HELLEINER, E. (2010) The G-20: A "Global Economic Government» in the Making? In: POHLMANN, C., REICHERT, S. and SCHILLINGER H.R (eds.) The G-20: A »Global Economic Government« in the Making? Bonn: Friedrich Ebert Foundation.

DEUTSCH, K.W. (1957) Security Communities. In: ROSENAU, J. (ed.) International Politics and Foreign Policy. New York: The Free Press.

DUPAS, G. e VIGEVANI, T. (orgs.), O Brasil e as novas dimensões da segurança internacional. SP: Alfa-Ômega, p. 17-42.

FLEMES, D. (2009) India-Brazil-South Africa (IBSA) in the New Global Order: Interests, Strategies and Values of the Emerging Coalition, International Studies vol. 46, No 4, p. 401-421.

FLEMES, D. (2013) Network Powers: Strategies of Change in the Multipolar System. Third World Quarterly, vol. 34, No 6, p. 1016-1036.

FONSECA JR., G. (1999) Anotaçôes sobre as condiçôes do sistema internacional no limiar do século XXI: a distribuição dos pólos de poder e a inserção internacional do Brasil. In: DUPAS, G. e VIGEVANI, T. (orgs.), O Brasil e as novas dimensões da segurança internacional. SP: Alfa-Omega, p. 17-42.

GRATIUS, S. (2011). Brasil y Europa hacia 2015. Policy Brief No 49, FRIDE.

GRATIUS, S. e GREVI, G. (2013). Brazil and the EU: partnership on security and human rights?, Policy Brief No 153, Fride/Madrid, 2013.

HAFNER-BURTON, E.M., KAHLER, M., \& ALEXANDER H.M. (2009) Network Analysis for International Relations. International Organization 63, p. 559-592.

JONES, C., WILLIAM S.H. \& BORGATTI, S.P. (1997) A General Theory of Network Governance. Exchange Conditions and Social Mechanisms. Academy of Management Review vol.22, No 4, p. 919-22.

KNOKE, D. (1990) Political Networks: The Structural Perspective, Structural Analysis in the Social Sciences. Cambridge, Cambridge University Press.

NYE, J.S. (2010) The future of American power. Dominance and decline in perspective. Foreign Affairs, vol.89, No 6, p. 2-12.

PAPPI, F. \& HENNING, C. (1998) Policy Networks. More than a Metaphor. Journal of Theoretical Politics vol.10, No 4, p. 535-75.

PATRICK, S. (2010) Irresponsible Stakeholders? The Difficulty of Integrating Rising Powers. Foreign Affairs vol.89, No 6, p. 45-54. 
PINHEIRO, L. Política externa brasileira. RJ: Jorge Zahar, 2004.

PINHEIRO, L. \& MILANI, C.R.S. (orgs.) Política externa brasileira. As práticas da política e a política das práticas. RJ, Editora FGV, 2013.

SARAIVA, M.G. (2010). A diplomacia brasileira e a visão sobre a inserção externa do Brasil: institucionalistas pragmáticos X autonomistas. Mural Internacional Ano 1 No 1. RJ, jan/jun. 2010, p. 45-52.

SARAIVA, M.G. (2014). The Brazilian Soft Power Tradition. Current History, v. 113, Fev./2014, p. 64-69.

SCHIRM, S. (2010) A. Leaders in need of followers: emerging powers in global governance. European Journal of International Relations No 16, p. 197-221.

SCHITTINI, J.P.M. (2011). A agenda do desenvolvimento na promoção dos direitos humanos: uma análise da política externa no governo Lula. Dissertação de mestrado. PPGRI/UERJ.

SLAUGHTER, Anne-Marie (2009) America’s Edge: Power in the Networked Century. Foreign Affairs vol. 88, No 1, p. 94-113.

TSAI, W. (2001) Knowledge Transfer in Intraorganizational Networks. Academy of Management Journal vol. 44, p. 996-1004.

VEIGA, P. da M. \& RIOS, S. (2011) A política externa no governo Dilma Rousseff: os seis primeiros meses. Brevíssimos CINDES No 32.

VIGEVANI, T.; FAVARON, G. de M.; RAMANZINI JR, H. e CORREIA, R.A (2008). O papel da integração regional para o Brasil: universalismo, soberania e percepção das elites. Revista Brasileira de Politica Internacional Ano 51 No 1. 2008, p. 5-27.

VIOLA, E. \& FRANCHINI, M. Brasil na governança global do clima, 2005-2012: a luta entre conservadores e reformistas. Contexto Internacional vol. 35, No 1, p. 43-76.

Recebido em 2 de novembro de 2014

Aceito em 18 de novembro de 2014

\section{Resumo}

Na última década, mudanças e inovações foram introduzidas nas redes intergovernamentais de política externa. Novas potências como Brasil adquiriram um peso relativo devido ao seu novo status atuando como definidor de agendas, moderador e construtor de coalizões. Esse artigo examina a relevância de diferentes redes de política externa como o Fórum Índia-Brasil-África do Sul (IBAS) e Brasil-África do Sul-Índia-China (BASIC) para a política externa brasileira desde 2003.

Palavras-chave: diplomacia e redes; ordem internacional em rede; Política Externa Brasileira.

\section{Abstract}

In the past decade, change and innovation have been induced through intergovernmental foreign policy networks. New powers like Brazil have gained relative weight due to their status as agenda-setters, brokers, and coalition-builders. This paper examines the relevance of different foreign policy networks such as India-Brazil-South Africa (IBSA) and Brazil-South Africa-IndiaChina (BASIC) for the Brazilian foreign policy since 2003.

Keywords: diplomacy and networks; networked international order; Brazilian Foreign Policy. 